\title{
The association of breastfeeding duration with later maternal feeding styles in infancy and toddlerhood: a cross-sectional analysis
}

Katherine Isselmann DiSantis ${ }^{{ }^{*}}$, Eric A Hodges ${ }^{2}$ and Jennifer Orlet Fisher ${ }^{3}$

\begin{abstract}
Background: Breastfeeding modestly reduces obesity risk, yet the mechanisms are not well understood. The goal of the current research was to evaluate the association of breastfeeding duration with a wide range of maternal feeding approaches in late infancy and toddlerhood.

Methods: A secondary analysis of cross-sectional data from an ethnically-diverse sample of 154 mothers of infants (aged 7-11 months) and toddlers (aged 12-24 months) was performed. Breastfeeding history was self-reported where $75 \%$ of mothers had weaned by the time of the interview. Multiple dimensions of maternal feeding approaches were measured using the Infant Feeding Styles Questionnaire which assesses pressuring, restriction, responsive, laissez-faire, and indulgent approaches to feeding. Analyses were performed separately for infants and toddlers and adjusted for maternal education level, ethnicity, and marital status.

Results: Mothers of infants who breastfed for longer durations tended to report greater responsiveness to infant satiety cues ( $p \leq 0.01)$ and reduced pressuring in feeding complementary foods $(p<0.05)$. Mothers of toddlers who breastfed for longer durations tended to report reduced pressuring in feeding complementary foods $(p<0.01)$.

Conclusion: These results suggest that breastfeeding may shape maternal feeding approaches related to responsiveness to infant cues as infants enter a period of complementary feeding, even after considering a range of demographic characteristics previously associated with breastfeeding behaviors. That responsiveness to feeding cues was not associated with breastfeeding duration in the toddler sample suggests that some aspects of this association might be isolated to infancy.
\end{abstract}

Keywords: Breastfeeding, Satiety response, Feeding behaviors, Feeding responsiveness

\section{Background}

A modest protective effect of breastfeeding on the development of obesity from childhood into adolescence and adulthood is well established [1-3]. A recent study using a sibling model found breastfed siblings were about 13 pounds lighter than non-breastfed siblings (based on same height) in early adolescence [4]. The association of breastfeeding with obesity risk appears to be dosedependent, supporting a causal relationship [2,5]. However, concerns over whether this evidence is a result of publication bias and confounding have led some experts

* Correspondence: disantisk@arcadia.edu

'Department of Community \& Global Public Health, Arcadia University, College of Health Sciences, 450 S. Easton Road, 219 Brubaker Hall, Glenside, PA 19038-3295, USA

Full list of author information is available at the end of the article to say the modest, positive effect of breastfeeding on obesity might not exist [6]. Despite these concerns, the most recent policy statement on breastfeeding from the American Academy of Pediatrics included obesity prevention as one of the numerous benefits of breastfeeding, citing a $24 \%$ reduction in obesity risk [7].

Potential mechanisms of the breastfeeding-obesity relationship have been explored [8], but remain poorly understood. The "hows" or behavioral aspects of breastfeeding are considered to be an important dimension [9]. The infant-centered nature of breastfeeding is thought to influence the amount of control mothers impose during feeding, entraining high levels of maternal sensitivity to infant feeding cues. Highly controlling approaches to feeding have been suggested to have detrimental influence on

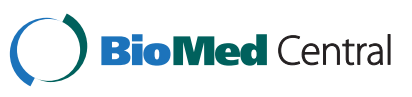


child regulation of appetite by being potentially unresponsive to child hunger and satiety cues [10,11], and are often assessed by measuring restrictive and pressuring approaches to feeding. Highly restrictive approaches to feeding, for instance, are thought to distract children from hunger/satiety cues by focusing attention on the availability of restricted foods [12], whereas highly pressuring approaches are thought to encourage eating in the absence of hunger or past fullness [12]. Prospective findings have provided some support for the contention that breastfeeding might entrain lower levels of maternal control [13-15], showing associations between longer breastfeeding duration and lower subsequent maternal restriction of infant feeding at 6- [13,15] and 12-months of age [14]. In turn, maternal control of infant feeding has been identified as a mediating factor between breastfeeding and energy intake in toddlerhood [16]. A study of 1012 mother-infant pairs found that maternal restriction during infant feeding (measured when infant was 12 months) partially attenuated the inverse relationship between breastfeeding duration and later body mass index [BMI] z-score [14]. These findings establish that breastfeeding is associated with less maternal control in the first 6-12 months of feeding. Less clear is whether the experience of breastfeeding shapes maternal control in feeding later in infancy and beyond, particularly as the child moves into the period of complementary feeding. Toddlerhood brings more complexity in caregiver-infant feeding interactions with a movement towards self-feeding and adult-like meal patterns. Thus, understanding whether the experience of breastfeeding shapes subsequent approaches to and sensitivity in child feeding holds interest.

Beyond expanding inquiry into the developmental stage of toddlerhood, widening the evaluation of maternal feeding beyond highly controlling approaches is important [16-18]. While maternal control has been a focal aspect of maternal feeding approaches in the study of child overweight and obesity [16-18], recent work has attempted to better understand the broader range of feeding approaches among ethnically diverse caregivers of children from birth to 5 years of age $[19,20]$. General and feeding-specific styles of parenting reflect the broad emotional climate in which specific goal-directed practices are used and in which socialization takes place [19]. Styles consider overall demands and expectations placed on the child as well as the caregiver's responsiveness to the child's unique needs [21]. Authoritative parenting, which balances demands on and responsiveness to the child, has been related to lower BMI in preschoolers and older children [19,22]. Conversely, indulgent approaches to general parenting and feeding, which involves high responsiveness to the child with few demands, has been related to higher BMI and less nutrient-dense food intake in preschoolers $[19,23,24]$. Potential associations of breastfeeding with authoritative or indulgent feeding approaches and practices have not been well investigated, yet the evidence for older children encourages the evaluation of a broader range of feeding styles earlier in life. Additionally, because ethnic differences in both rates of child overweight and obesity [25] and in parent feeding styles $[19,26,27]$ have been identified, studies of maternal feeding are most informative when performed in diverse samples.

This investigation addresses these gaps in the literature by evaluating the association of breastfeeding duration with a wide range of maternal feeding styles later in infancy and toddlerhood including pressuring, restrictive, responsiveness, indulgence, and laissez-faire feeding styles [20] in an ethnically diverse sample. It was hypothesized that mothers with higher breastfeeding duration levels would report higher responsiveness, less restriction, and less pressuring in feeding their infant or toddler. Given relationships between indulgent feeding and overweight in older children $[19,23]$, it was hypothesized that longer breastfeeding durations would be related to lower amounts of indulgent feeding in infancy and toddlerhood.

\section{Methods}

A secondary analysis was performed using data from a cross-sectional study of dietary assessment methodology among ethnically diverse infants and toddlers [21]; the methods of the study have been previously described [21]. Briefly, convenience sampling was used to recruit motherchild dyads, including recruiting through a volunteer database maintained at the US Department of Agriculture (USDA) Children's Nutrition Research Center and recruiting in-person and/or posting fliers at targeted locations (including childcare classes, festival, doctors' offices, retail stores, and churches). Data were collected in 2005 and 2006. Reflecting the design of the study, children in the dyads were either infants aged $7-11$ months $(n=79)$ or toddlers aged 12-24 months $(\mathrm{n}=74)$. Potential participants were also intentionally sampled to include equal representation of Hispanics, blacks, and whites. Maternal inclusion criteria were self-identification in one of these race/ethnicity groups and having primary responsibility for infant feeding at home. Infant inclusion criteria were being within the study age range at the time of enrollment, born at full-term (37-42 wk), and birth weight-for-age of $>5$ th percentile [28]. Infant exclusion criteria were significant feeding problems which results in a highly restrictive diet (e.g. severe food allergies, severe reflux), chronic medical conditions, and/or medication use; maternal reports of such problems were considered by the research team on a case-by-case basis.

\section{Measures}

\section{Family demographic and maternal characteristics}

Demographic information was collected by maternal self-report including maternal race/ethnicity, maternal 
education level, parity at birth of the child participant, marital status, and household income level. Mothers also reported whether their family participated in a US governmental food and nutrition assistance program (Women, Infants and Children [WIC]). Maternal height (Harpenden tadiometer; Holtain Limited) and weight [Doctor Scale 431/432KL series (capacity: 400_0.25 lb or 181.4 _ $0.1 \mathrm{~kg}$ ); Health-O-Meter, Bridgeview IL] were measured in duplicate by trained research staff according to the methods of Lohman et al. [29], where repeat measurements were performed in cases of nonagreement (within $0.5 \mathrm{~kg}$ or $0.5 \mathrm{~cm}$ ). BMI scores were calculated based on these measures.

\section{Breastfeeding and infant feeding history}

Breastfeeding duration was self-reported by the mother in months. Mothers were asked "Has your child ever been breastfed or fed breastmilk?". If mothers responded "yes", they were asked "Are you currently breastfeeding?". For mothers who were currently breastfeeding at the time of interview, their infant's age in months at the time of interview was recorded as the duration of "any breastfeeding". Last, if mothers were not currently breastfeeding, they were asked "How old was your child when you stopped breastfeeding?". Duration was categorized in three categories based on US public health recommendations and population trends [7]. While current US recommendations endorse exclusive breastfeeding for 6 months [7], national breastfeeding rates show marked shifts between birth and 3 months, and again from 3 to 6 months; the percent of mothers breastfeeding drops from $75 \%$ at birth to $35 \%$ at 3 months, and to $14 \%$ at 6 months [30]. Therefore, three categories of breastfeeding duration corresponding to those recommendations and trends were utilized: $0-2.99$ months $[\mathrm{BF}<3], 3-6$ months [BF3-6], $>6$ months $[\mathrm{BF}>6]$. Previously cited dose-dependent relationships between breastfeeding and obesity [2,5] also support the use of a graded classification of duration. To determine age of formula supplementation, mothers were asked, "How old was your baby when you started feeding formula?" (If mothers answered "No" to the question "Has your child ever been fed formula?", this question was skipped). To determine age at introduction of complementary foods, mothers were asked at what age (in months) their infant was first fed the following baby foods: cereal, fruit, vegetables, meats, and mixed dishes. The lowest age was recorded as the age at introduction of complementary foods.

\section{Feeding styles}

The Infant Feeding Styles Questionnaire [IFSQ] was utilized to assess maternal feeding styles reflecting a broad range of maternal beliefs and behaviors surrounding infant and toddler feeding [20]. Styles were informed by Costanzo and Woody's [31] theory of domain-specific parenting styles, where maternal feeding styles are based on concerns (e.g. concern over eating unhealthy foods, concern about child weight status) and constraints (e.g. resources, knowledge). The IFSQ includes items that assess feeding styles in five domains: (1) Laissez-faire, (2) Pressuring/controlling, (3) Restrictive/controlling, (4) Responsive, and (5) Indulgent. Each domain contains multiple subscales for a total of 13 subscales with 83 items; exemplars are presented in Table 1. Laissez-faire feeding was measured with two subscales, Diet Quality and Attention, and higher scores represent fewer caregiver limits and less interaction. Pressuring/controlling feeding was measured with three subscales, Finishing Cereal, and Soothing. Higher scores on Finishing subscale represent greater caregiver pressure on infant to finish a bottle/food during a meal; higher scores on the Cereal subscale relate to offering cereal in a bottle to their infant and to beliefs that cereal consumption before the age of six months is needed for infant to sleep and feel full; and high scores on the Soothing subscale represent greater caregiver pressure to eat in an effort stop an infant's/toddler's crying. Restrictive/controlling feeding was measured with two subscales, Amount and Diet Quality, and higher scores represent more caregiver limits on the quantity and quality (in terms of healthfulness) of food their infant/toddler consumes. Responsive feeding was measured with two subscales, Satiety and Hunger Cue and Attention/Interactions. Higher scores on the Satiety and Hunger Cues subscale represent greater caregiver responsiveness to infant/toddler hunger and satiety cues and a greater belief in infant/toddler ability to self-regulate. Higher scores on the Attention/ Interactions subscale represent more general attentiveness during feedings. Indulgent feeding was measured with three subscales, Coaxing, Pampering, and Soothing, and higher scores represent less caregiver limit setting on the quantity or quality of food consumed with greater feeding to coax, soothe, or pamper the infant/toddler. Feeding behavior items were scored from "1"-never to "5"-always and feeding beliefs were scored from "1"-disagree to " 5 "-agree. The behavior portion of the Laissezfaire Diet Quality Subscale (4 questions) was scored in descending order where " 1 "-always to " 5 "-never.

In previous studies, the internal consistency of subscale items ranged from moderate to strong and all but three of the subscales had desirable reliability ( $\mathrm{H}$ coefficients $\geq 0.80$ ) in a sample of 154 3-20 month old lowincome, African American infants/toddlers [20]. The remaining three subscales (restriction in amount of food, pressuring to eat cereal, pressuring to finish meal) had satisfactory internal consistency ( $\mathrm{H}$ coefficients $\geq 0.75$ ) [20]. Evidence of predictive validity is demonstrated by 
Table 1 Example items from IFSQ by subscale

\begin{tabular}{|c|c|}
\hline Style Domains & Sub-Scale Name \\
\hline Responsive & Satiety (7 items) \\
\hline Behavior & (Child) lets me know when s/he is full \\
\hline Belief & Child knows when s/he is full \\
\hline Responsive & Attention (5 items) \\
\hline Behavior & Talk to (child) to encourage him/her to eat \\
\hline Belief & Important to help or encourage a toddler to eat \\
\hline Restrictive & Amount (4 items) \\
\hline Behavior & I carefully control how much (child) eats \\
\hline Belief & Important parent decides how much infant should eat \\
\hline Restrictive & Diet Quality (7 items) \\
\hline Behavior & I let (child) eat fast food \\
\hline Belief & A toddler should never eat fast food \\
\hline Pressuring & Finishing (8 items) \\
\hline Behavior & Try to get (child) to finish his/her food \\
\hline Belief & Important for toddler finish all food on his/her plate \\
\hline Pressuring & Cereal (5 items) \\
\hline Behavior & Give/gave (child) cereal in the bottle \\
\hline Belief & An infant $<6$ mo needs more than formula or breastmilk to be full \\
\hline Pressuring & Soothing (4 items) \\
\hline Behavior & When (child) cries, I immediately feed him/her \\
\hline Belief & Best way to make infant stop crying is to feed \\
\hline Indulgent & Coaxing (8 items) \\
\hline Behavior & Allow child to eat desserts/sweets to make sure s/he gets enough \\
\hline Belief & Toddlers should be allowed to eat desserts/sweets to make sure they get enough \\
\hline Indulgent & Soothing (8 items) \\
\hline Behavior & Allow child watch tv while eating to keep him/her from crying \\
\hline Belief & Toddlers should be allowed to watch tv while eating to keep them from crying \\
\hline Indulgent & Pampering (8 items) \\
\hline Behavior & Allow child to eat desserts/sweets to keep him/her happy \\
\hline Belief & Toddlers should be allowed to eat desserts/sweets to keep them happy \\
\hline Laissez-faire & Attention (5 items) \\
\hline Behavior & When (name of child) has/had a bottle, I prop/propped it up \\
\hline Belief & I think it is okay to prop an infant's bottle \\
\hline Laissez-faire & Diet Quality (6 items) \\
\hline Behavior & I keep track of what food (child) eatst \\
\hline Belief & A toddler should be able to eat whatever s/he wants for snacks \\
\hline
\end{tabular}

†This question was reverse coded.

associations of four of the thirteen constructs with infant weight-for-length $\mathrm{z}$-score [20]. In the current study, the internal consistency of the IFSQ subscales was assessed for the entire sample. All subscales under the Indulgent and Pressuring domains were good or acceptable $(\alpha \geq 0.7)$. For the Restrictive subscales, the internal consistency of the Restrictive Diet Quality subscale was good after removing two questions intended for mothers of toddlers-only $(\alpha \geq 0.7)$. For the Responsive scales, both the Satiety and Attention subscales had questionable internal consistency $(\alpha \geq 0.6)$; the internal consistency of the Satiety scale was acceptable when evaluated in the infant sample alone $(\alpha=0.7)$. The internal consistency of the Laissez-faire Diet Quality subscale was acceptable $(\alpha=0.7)$, but the Laissez-faire Attention subscale had questionable internal consistency $(\alpha<0.6)$.

\section{Infant or toddler anthrometrics}

Anthropometrics included length and weight measured in triplicate by trained research staff. Electronic scales 
[3862 MP 6; Sartorius (readability: $0.1 \mathrm{~g}$ )] were used to measure weight and infant length boards (Holtain Limited, Crymych, United Kingdom) were used to measure length of both infants and toddlers. The 2000 Centers for Disease Control and Prevention growth charts were used to calculate weight-for-length $\mathrm{z}$ scores (referred to as relative weight) [32].

\section{Statistical analyses}

Descriptive variables (family demographic, maternal characteristics, infant relative weight (weight-for-length $\mathrm{z}$-score)) and infant feeding variables (breastfeeding duration, supplementation, solid introduction) were examined for the infant and toddler samples separately, and compared between the three breastfeeding groups $(\mathrm{BF}<3, \mathrm{BF} 3-6, \mathrm{BF}>6)$, using ANOVA and Chi-square analyses as appropriate. Potential maternal covariates included education (college degree or more vs. less than college degree) [30], race/ethnicity [30], income [30], age [30], marital status (married vs. not) [30], and maternal weight status (overweight/obese vs. not) [33]. Potential child covariates included relative weight [34] and gender [35] which have been previously associated with breastfeeding and/or parent feeding styles. Potential covariates were included in the ANCOVA models based on significant associations $(\mathrm{p} \leq 0.05)$ with the IFSQ subscales, based on ANOVA analyses and Spearman correlation as appropriate, and were considered separately for the infants and toddler groups. All significant associations are presented in Tables 2 and 3 for the infant and toddler samples, respectively. If a potential covariate was significantly associated with a subscale from more than one of the five feeding domains, it was included as a covariate. Neither of the potential child covariates (relative weight, gender) was significantly associated with any of the subscales in either the infant or toddler samples; thus, they were not included in ANCOVA models. Based on those preliminary analyses, maternal education, marital status, and maternal ethnicity were included as potential covariates in the ANCOVA models for both infants and toddler samples. Bonferroni post hoc tests were used to understand differences in effects between groups.

\section{Results \& discussion \\ Sample}

Tables 4 and 5 present the demographic characteristics of mothers of infants and toddlers, respectively. A high proportion of mothers were employed and college

Table 2 Associations identified between potential covariates and IFSQ subscales in the infant sample

\begin{tabular}{|c|c|c|c|c|c|}
\hline & $\begin{array}{l}\text { Responsive } \\
\text { subscales }\end{array}$ & $\begin{array}{l}\text { Restrictive } \\
\text { subscales }\end{array}$ & $\begin{array}{l}\text { Pressuring to eat } \\
\text { subscales }\end{array}$ & $\begin{array}{l}\text { Indulgent } \\
\text { subscales }\end{array}$ & $\begin{array}{l}\text { Laissez-Faire } \\
\text { subscales }\end{array}$ \\
\hline \multicolumn{6}{|l|}{ Infant Gender } \\
\hline \multicolumn{6}{|l|}{ Infant Relative Weight ${ }^{a}$} \\
\hline \multirow[t]{4}{*}{ Maternal Education Level } & $\begin{array}{l}\text { Amount of } \\
\text { Food Consumed** }\end{array}$ & & Cereal** & Coaxing** & Attention** \\
\hline & & & Finishing Food* & Pampering* & \\
\hline & Diet Quality** & & & Permissive** & \\
\hline & & & & Soothe* & \\
\hline \multirow[t]{4}{*}{ Maternal Ethnicity } & $\begin{array}{l}\text { Amount of } \\
\text { Food Consumed** }\end{array}$ & & Cereal** $^{* *}$ & Coaxing** & Attention** \\
\hline & & & Finishing Food** & Pampering* & \\
\hline & & & To Soothe** & Permissive** $^{* *}$ & \\
\hline & & & & Soothe* & \\
\hline \multirow[t]{2}{*}{ Family Income level } & & & Cereal* & & \\
\hline & & & Finishing Food* & & \\
\hline \multirow[t]{4}{*}{ Marital Status } & Diet Quality* & $\begin{array}{l}\text { Satiety and Hunger } \\
\text { Cues** }^{*}\end{array}$ & Cereal** & Coaxing** & Attention** \\
\hline & & & & Pampering* & \\
\hline & & & & Permissive** $^{* *}$ & \\
\hline & & & & Soothe* & \\
\hline \multicolumn{3}{|l|}{ Maternal Weight Status } & Cereal* & & \\
\hline \multicolumn{6}{|c|}{$\begin{array}{l}\text { a The association between infant relative weight and the IFSQ subscales were assessed by Spearman Correlation, due to the continuous nature of the covariate, } \\
\text { while Analysis of Variance analyses were performed for all other covariates. } \\
\text { Note: All categorical covariates were coded as follows: Gender (Male=1, Female=2); Maternal Education Level (College Grad or Higher }=1 \text {, Less than College } \\
\text { Grad=0); Maternal Ethnicity (White=1, Black=2, } 3=\text { Hispanic); Income level }(1=\text { less than } \$ 35,000,2=\$ 35,000-49,999,3=\$ 50,000-74,999,4=\$ 75,000-99,999,5=100,000 \\
\text { or greater); Marital Status (Married=1, Not Married=0); Maternal weight status (Overweight/Obese }=1 \text {, Not overweight/obese }=0 \text { ). }\end{array}$} \\
\hline
\end{tabular}


Table 3 Associations identified between potential covariates and IFSQ subscales in the toddler sample

\begin{tabular}{|c|c|c|c|c|c|}
\hline & $\begin{array}{l}\text { Responsive } \\
\text { subscales }\end{array}$ & $\begin{array}{l}\text { Restrictive } \\
\text { subscales }\end{array}$ & $\begin{array}{l}\text { Pressuring to eat } \\
\text { subscales }\end{array}$ & $\begin{array}{l}\text { Indulgent } \\
\text { subscales }\end{array}$ & $\begin{array}{l}\text { Laissez-Faire } \\
\text { subscales }\end{array}$ \\
\hline \multicolumn{6}{|l|}{ Infant Gender } \\
\hline \multicolumn{6}{|l|}{ Infant Relative Weight ${ }^{a}$} \\
\hline \multirow[t]{3}{*}{ Maternal Education Level } & Diet Quality** & $\begin{array}{l}\text { Satiety and Hunger } \\
\text { Cues* }^{*}\end{array}$ & Cereal** & Coaxing* & \\
\hline & & & & Permissive* & \\
\hline & & & & Soothe* & \\
\hline \multirow[t]{2}{*}{ Maternal Ethnicity } & & & Cereal** & Coaxing* & Attention* \\
\hline & & & To Soothe* & Soothe* & \\
\hline \multicolumn{3}{|l|}{ Family Income Level } & & Pampering* & \\
\hline \multirow[t]{3}{*}{ Marital Status } & Diet Quality* & & & Coaxing** & Attention* \\
\hline & $\begin{array}{l}\text { Amount of } \\
\text { Food Consumed* }\end{array}$ & & Cereal** & Permissive** $^{* *}$ & \\
\hline & & & & Soothe** & \\
\hline \multicolumn{6}{|l|}{ Maternal Weight Status } \\
\hline \multicolumn{6}{|c|}{ 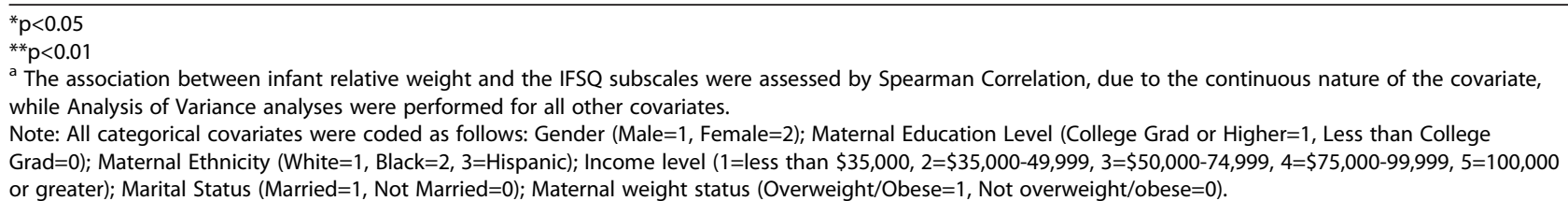 } \\
\hline
\end{tabular}

graduates. Mothers of infants and toddlers who breastfed longer $(\mathrm{BF}>6)$ were more likely to be college educated and less likely to participate in WIC $(\mathrm{p}<0.05)$ compared to mothers who breastfed for shorter durations $(\mathrm{BF}<3, \mathrm{BF}-6)$. For mothers of infants only, mothers who breastfed longer $(\mathrm{BF}>6)$ were less likely to report current employment $(\mathrm{p}<0.05)$ compared to mothers who breastfed for shorter durations $(\mathrm{BF}<3$, BF3-6). For mothers of toddlers only, mothers who breastfed longer $(\mathrm{BF}>6)$ were more likely to be nonHispanic white $(\mathrm{p}<0.05)$ compared to mothers who breastfed for shorter durations $(\mathrm{BF}<3, \mathrm{BF}-6)$. There were no significant differences in relative weight between breastfeeding duration groups in either the infant or toddler samples.

\section{Breastfeeding and infant feeding history}

Table 4, presents mean breastfeeding and exclusive breastfeeding (only human milk) duration for mothers of infants across the three groups. Twenty-seven mothers (34.1\%) were still breastfeeding (non-exclusively) at the time of the interview. There were significant differences in age at introduction of complementary foods $(\mathrm{p}<0.01)$, with post-hoc analyses showing that infants in the $\mathrm{BF}<3$ group $(M=3.6$ months, $S D=1.1)$ and the BF3-6 months group $(M=3.8$ months, $S D=1.7)$ received complementary foods earlier than the $\mathrm{BF}>6$ group $(M=4.9$ months, $S D=1.1$ ). Table 5 presents mean breastfeeding and exclusive breastfeeding lengths for mothers of toddlers across the three groups. Twelve mothers (16.0\%) were still breastfeeding (non-exclusive) at the time of the interview. There were significant differences in age at introduction of complementary foods $(\mathrm{p}<0.01)$, with post-hoc analyses finding that toddlers in the $\mathrm{BF}<3$ group $(M=4.2$ months, $S D=1.4)$ and the BF3-6 group ( $M=4.4$ months, $S D=1.6)$ received complementary foods earlier than the $\mathrm{BF}>6$ group $(M=5.2$ months, $S D=1.5)$.

\section{Breastfeeding duration and maternal feeding styles}

Mothers of infants who breastfed longer reported greater responsiveness to infant satiety cues $(\mathrm{p} \leq 0.01)$ and less pressuring of their infant (related to infant cereal consumption) $(\mathrm{p} \leq 0.01)$ (Table 6). Post-hoc analyses are presented in Figure 1 and show for the responsiveness to satiety cues subscale that the mothers in the $\mathrm{BF}>6$ $(M=4.7, S D=0.4)$ and the BF3-6 groups $(M=4.6, S D=0.4)$ reported higher responsiveness $(\mathrm{p}<0.05)$ compared to the $\mathrm{BF}<3$ group $(M=4.2, S D=0.7)$. The BF3-6 and $\mathrm{BF}>6$ groups did not differ $(\mathrm{p}>0.05)$ in the amount of responsiveness reported by mothers of infants. Post-hoc analyses for the pressuring to eat cereal subscale showed that the mothers in the $\mathrm{BF}>6$ group $(M=1.6, S D=0.8)$ reported exerting less pressure to eat cereal $(\mathrm{p}<0.01)$ compared to the BF3-6 $(M=2.8, S D=1.0)$ and $\mathrm{BF}<3$ $(M=2.6, S D=1.1)$ groups. The $\mathrm{BF} 3-6$ and $\mathrm{BF}<3$ groups did not differ $(\mathrm{p}>0.05)$ in the amount of pressure reported by mothers of infants. There were no significant differences ( $p>0.05)$ between the breastfeeding duration groups for any of the subscale scores under the indulgent, restrictive, or laissez-faire feeding styles. 
Table 4 Demographics of infant sample by breastfeeding groups

\begin{tabular}{|c|c|c|c|c|c|}
\hline Demographics & $\begin{array}{l}\text { All infants } \\
\mathrm{n}=79\end{array}$ & $\begin{array}{l}\mathrm{BF}<3 \mathrm{mos} \\
\mathrm{n}=21\end{array}$ & $\begin{array}{l}\text { BF } 3-6 \mathrm{mos} \\
\mathrm{n}=\mathbf{2 8}\end{array}$ & $\begin{array}{l}\mathrm{BF}>6 \mathrm{mos} \\
\mathrm{n}=30\end{array}$ & $\begin{array}{l}\mathrm{p}- \\
\text { value }\end{array}$ \\
\hline Mother Age, mean (SD) & $30.4(5.4)$ & $28.9(5.9)$ & $30.0(5.3)$ & $31.8(5.0)$ & 0.16 \\
\hline Months of Any Breastfeeding, mean (SD)** & $5.5(3.6)$ & $0.8(0.8)$ & $4.3(1.2)$ & $9.5(1.5)$ & 0.00 \\
\hline Months of Exclusive Breastfeeding, mean (SD) & $2.4(2.2)$ & $0.5(0.8)$ & $1.8(1.7)$ & $3.6(2.3)$ & 0.00 \\
\hline Age at Introduction of Complementary foods (Months), mean (SD) & $4.3(1.3)$ & $3.6(1.1)$ & $3.8(1.5)$ & $4.9(1.1)$ & 0.00 \\
\hline Infant Weight-for-length z-score & $-0.02(0.9)$ & $-0.03(1.0)$ & $0.20(0.8)$ & $0.14(0.9)$ & 0.14 \\
\hline Never put Cereal in Bottle?† & $45.9 \%$ & $33.3 \%$ & $32.1 \%$ & $72.0 \%$ & 0.01 \\
\hline Infant Gender & & & & & 0.36 \\
\hline Male & $46.3 \%$ & $33.3 \%$ & $53.6 \%$ & $48.4 \%$ & \\
\hline Female & $53.8 \%$ & $66.7 \%$ & $46.4 \%$ & $51.6 \%$ & \\
\hline Mom Race Ethnicity & & & & & 0.06 \\
\hline White, non-Hispanic & $37.5 \%$ & $19 \%$ & $32.1 \%$ & $54.8 \%$ & \\
\hline Black, African American & $30 \%$ & $42.9 \%$ & $25 \%$ & $25.8 \%$ & \\
\hline Hispanic & $32.5 \%$ & $38.1 \%$ & $42.9 \%$ & $19.4 \%$ & \\
\hline Parity & & & & & 0.07 \\
\hline Primiparious at Child's Birth & $45 \%$ & $66.7 \%$ & $35.7 \%$ & $38.7 \%$ & \\
\hline Household Income Level & & & & & 0.61 \\
\hline$<\$ 35,000$ & $21.8 \%$ & $35 \%$ & $21.4 \%$ & $13.3 \%$ & \\
\hline$\$ 35,000-45,999$ & $23.1 \%$ & $25 \%$ & $21.4 \%$ & $23.3 \%$ & \\
\hline$\$ 50,000-\$ 74,999$ & $20.5 \%$ & $15 \%$ & $25 \%$ & $20 \%$ & \\
\hline$\$ 75,000-\$ 99,999$ & $16.7 \%$ & $10 \%$ & $21.4 \%$ & $16.7 \%$ & \\
\hline$\geq \$ 100,000$ & $17.9 \%$ & $15 \%$ & $10.7 \%$ & $26.7 \%$ & \\
\hline$\underline{\text { Maternal Education Level* }}$ & & & & & 0.01 \\
\hline College Graduate? & $50 \%$ & $42.9 \%$ & $32.1 \%$ & $71.0 \%$ & \\
\hline Mother Employed?* & $58.8 \%$ & $76.2 \%$ & $71.4 \%$ & $35.5 \%$ & 0.01 \\
\hline Mom Overweight or Obese & $72.6 \%$ & $85.0 \%$ & $69.6 \%$ & $66.7 \%$ & 0.34 \\
\hline Family Participates in WIC* & $40 \%$ & $47.6 \%$ & $57.1 \%$ & $19.4 \%$ & 0.01 \\
\hline
\end{tabular}

Mothers of toddlers who breastfed longer reported lower pressuring in relation to infant cereal consumption $(\mathrm{p} \leq 0.01)$ (Table 7). Post-hoc analyses showed that the $\mathrm{BF}>6$ group $(M=1.4, S D=0.5)$ reported exerting less pressure to eat cereal $(\mathrm{p}<0.01)$ compared to the BF3-6 group $(M=2.4, S D=0.8)$ and $\mathrm{BF}<3$ group $(M=2.6, S D=1.2)$. The BF3- 6 and $\mathrm{BF}<3$ groups did not differ in the amount of pressure reported by mothers. It should be noted that the questions regarding pressuring to eat cereal center on the introduction of complementary foods to infants and focus on the first six months of life. For the $\mathrm{BF}<3$ group and BF3-6 groups, $86.3 \%$ and $78.6 \%$ of mothers of toddlers reported introducing cereal prior to the age of six months, respectively, compared to $57.5 \%$ for mothers of toddlers in the $\mathrm{BF}>6$ group. There were no significant differences ( $p>0.05)$ between the breastfeeding duration groups for any of the subscale scores under the responsive, indulgent, restrictive, or laissez-faire feeding styles.

\section{Discussion}

This research studied breastfeeding and its relationship with a wide range of feeding styles during infancy and toddlerhood in an effort to advance scientific understanding of potential behavioral factors that underlie the protective effect of breastfeeding on child obesity risk. The main finding was that mothers who breastfed 3 months or longer reported higher levels of responsiveness to infant satiety and hunger cues than mothers who breastfed for less than 3 months, after taking into consideration potentially important covariates (maternal education, marital status, and ethnicity). These results suggest that mothers who breastfeed may show greater acknowledgement of infants' ability to communicate fullness and responsiveness to those cues during infant feeding. This association was not observed among mothers of toddlers, suggesting that the relationship may be limited to infancy. 
Table 5 Demographics of toddler sample and by breastfeeding groups

\begin{tabular}{|c|c|c|c|c|c|}
\hline Demographics & All toddlers & $\mathrm{BF}<3 \mathrm{mos}$ & BF 3-6mos & $\mathrm{BF}>6 \mathrm{mos}$ & p-value \\
\hline & $\mathrm{n}=75$ & $\mathrm{n}=\mathbf{2 1}$ & $\mathrm{n}=14$ & $\mathrm{n}=40$ & \\
\hline Mother Age, mean (SD) & $30.5(5.5)$ & $30.8(7.3)$ & $27.9(4.5)$ & $31.2(4.6)$ & 0.15 \\
\hline Months of Any Breastfeeding, mean (SD)** & $7.9(6.5)$ & $0.4(0.5)$ & $4.9(1.0)$ & $12.7(4.8)$ & 0.00 \\
\hline Months of Exclusive Breastfeeding, mean (SD) & $3.0(2.8)$ & $0.2(0.3)$ & $1.7(1.5)$ & $4.5(2.0)$ & 0.01 \\
\hline Age at Introduction of Complementary Foods (Months), mean (SD) & $4.9(1.5)$ & $4.2(1.4)$ & $4.4(1.6)$ & $5.2(1.5)$ & 0.00 \\
\hline Toddler Weight-for-length z-score & $-0.13(1.0)$ & $-0.10(1.1)$ & $0.36(0.9)$ & $0.32(0.9)$ & 0.08 \\
\hline Never put Cereal in Bottle?† & $45.9 \%$ & $47.4 \%$ & $30.8 \%$ & $83.3 \%$ & 0.01 \\
\hline Infant Gender & & & & & 0.71 \\
\hline Male & $42.1 \%$ & $38.1 \%$ & $35.7 \%$ & $46.3 \%$ & \\
\hline Female & $57.9 \%$ & $61.9 \%$ & $64.3 \%$ & $53.7 \%$ & \\
\hline Mom Race Ethnicity* & & & & & 0.03 \\
\hline White, non-Hispanic & $32.9 \%$ & $14.3 \%$ & $21.4 \%$ & $46.3 \%$ & \\
\hline Black, African American & $31.6 \%$ & $47.6 \%$ & $50 \%$ & $17.1 \%$ & \\
\hline Hispanic & $35.5 \%$ & $38.1 \%$ & $28.6 \%$ & $36.6 \%$ & \\
\hline Parity & & & & & 0.93 \\
\hline Primiparious at Child's Birth & $52.6 \%$ & $52.4 \%$ & $57.1 \%$ & $51.2 \%$ & \\
\hline Household Income Level & & & & & 0.24 \\
\hline$<\$ 35,000$ & $28.3 \%$ & $28.6 \%$ & $50 \%$ & $15.0 \%$ & \\
\hline$\$ 35,000-45,999$ & $18.7 \%$ & $23.8 \%$ & $7.1 \%$ & $20.0 \%$ & \\
\hline$\$ 50,000-\$ 74,999$ & $20.0 \%$ & $25.8 \%$ & $7.1 \%$ & $22.5 \%$ & \\
\hline$\$ 75,000-\$ 99,999$ & $14.7 \%$ & $9.4 \%$ & $7.1 \%$ & $20.0 \%$ & \\
\hline$\geq \$ 100,000$ & $21.3 \%$ & $14.3 \%$ & $28.6 \%$ & $22.5 \%$ & \\
\hline Maternal Education Level* & & & & & 0.02 \\
\hline College Graduate? & $61.8 \%$ & $38.1 \%$ & $57.1 \%$ & $75.6 \%$ & \\
\hline Mother Employed? & $57.9 \%$ & $52.4 \%$ & $57.1 \%$ & $61.0 \%$ & 0.81 \\
\hline Mom Overweight or Obese & $52.9 \%$ & $47.4 \%$ & $63.6 \%$ & $29.4 \%$ & 0.69 \\
\hline Family Participates in WIC** & $21.1 \%$ & $38.1 \%$ & $42.9 \%$ & $4.9 \%$ & 0.00 \\
\hline
\end{tabular}

Our findings suggest that responsiveness is at the core of feeding style differences between mothers of varying breastfeeding duration, which augments past research on the positive relationship between breastfeeding and child-centered which focused on control [8,36-38]. It is plausible that mothers who breastfed for a longer duration differ in attitudes and beliefs which influence level of responsiveness/pressuring feeding styles in a manner unexplained by the socio-demographic characteristics taken into account in this study. However, it could be that the more a mother engages in a behavior, the more likely she is to permanently adopt the behavior. In this case, longer breastfeeding duration would allow a mother to engage in infant-centered feeding interactions for a longer time, increasing the likelihood that these interaction patterns would continue, after initiation of complementary feeding [39]. This possibility suggests that the infant-centered nature of breastfeeding, if of sufficient duration, results in greater responsiveness to infant feeding cues, which is consistent with prior research findings in this area $[13,15,16]$. While Brown and Lee [38] found a shorter duration of breastfeeding (6 weeks) was sufficient to predict satiety responsiveness among toddlers regardless of current feeding style, they did not report relationships between duration and feeding style. It is also interesting that a difference in maternal responsiveness was identified between mothers breastfeeding for less than three months and those breastfeeding for 3 or more months. Currently only $35 \%$ of mothers in the US are breastfeeding exclusively at three months [21], which suggests greater supports need to be put in place to extend duration beyond 3 months in order to maximize the benefits of breastfeeding in regards to responsive feeding.

Despite the inclusion of multiple dimensions of feeding styles in the current study, breastfeeding duration 
Table 6 ANCOVAt of Breastfeeding duration as a function of maternal feeding styles among infants

\begin{tabular}{|c|c|c|c|c|}
\hline IFSQ Subscale & BF <3 Mon $(n=21)$ & BF 3-6 Mon $(n=28)$ & BF>6 Mon $(n=30)$ & p-value \\
\hline \multicolumn{5}{|l|}{ Responsiveness Subscales } \\
\hline Satiety and Hunger Cues* & $4.2(0.7)$ & $4.6(0.4)$ & $4.7(0.4)$ & 0.02 \\
\hline Attention \& Interactions & $3.4(0.7)$ & $3.3(0.7)$ & $3.5(0.7)$ & 0.65 \\
\hline \multicolumn{5}{|l|}{ Restriction Subscales } \\
\hline Amount of Food Consumed & $3.3(0.9)$ & $3.2(1.0)$ & $2.8(1.1)$ & 0.37 \\
\hline Diet Quality & $2.8(0.6)$ & $2.8(0.6)$ & $3.0(0.6)$ & 0.92 \\
\hline \multicolumn{5}{|l|}{ Pressuring to Eat Subscales } \\
\hline To Soothe & $2.4(0.9)$ & $2.0(0.7)$ & $2.1(0.8)$ & 0.11 \\
\hline Finishing Food & $2.4(0.7)$ & $2.4(0.6)$ & $2.1(0.8)$ & 0.80 \\
\hline Cereal* $^{*}$ & $2.6(1.1)$ & $2.8(1.0)$ & $1.6(0.8)$ & 0.00 \\
\hline \multicolumn{5}{|l|}{ Indulgent Subscales } \\
\hline Coaxing & $1.4(0.5)$ & $1.3(0.3)$ & $1.3(0.4)$ & 0.62 \\
\hline Pampering & $1.4(0.5)$ & $1.3(0.3)$ & $1.2(0.4)$ & 0.86 \\
\hline Permissive & $1.7(0.7)$ & $1.8(0.6)$ & $1.7(0.6)$ & 0.38 \\
\hline Soothing & $1.4(0.5)$ & $1.1(0.2)$ & $1.2(0.3)$ & 0.32 \\
\hline \multicolumn{5}{|l|}{ Laissez-faire Subscales } \\
\hline Attention & $1.8(0.7)$ & $1.99(0.7)$ & $1.8(0.6)$ & 0.25 \\
\hline Diet Quality & $2.2(0.8)$ & $2.40(1.0)$ & $2.1(0.7)$ & 0.55 \\
\hline
\end{tabular}

†Covariates included were maternal ethnicity, marital status, and maternal education level.

${ }^{*} \mathrm{p}<0.05$

Note: IFSQ Subscales were scored from 1-5, where behaviors are scored from " 1 "-never to " 5 "-always and beliefs are scored from " 1 "-disagree to " 5 "-agree. The behavior portion of the Laissez-Faire Diet Quality Subscale was scored in descending order where " 1 "-always to " 5 "-never. IFSQ=Infant Feeding Styles Questionnaire; BF<3 Mon=Breastfed less than 3 months group; BF3-6 Mon= Breastfed for 3-6 months group; BF $>6$ Mon= Breastfed for more than 6 months group.

was largely unassociated with indulgent, restrictive, laissez-faire, and pressuring maternal feeding styles. Breastfeeding duration was associated with less maternal pressure among both infants and toddlers, but only in relation to early introduction of infant cereal. Thus mothers who breastfed for greater than 6 months were less likely to offer cereal in the bottle and/or to hold beliefs that the use of infant cereal in early infancy $(<6$ months) offers benefits (mainly infant fullness and sleeping through the night). Past research on pressuring has primarily relied on the Child Feeding Questionnaire, which focuses on pressuring a child to finish a meal, to

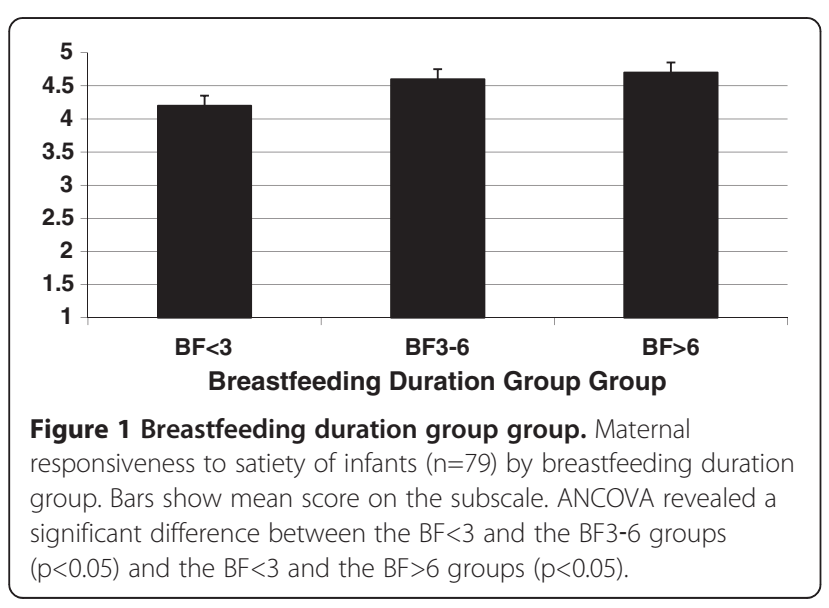

eat without hunger, and to eat "enough" from the caregiver's perspective [17]. The measure used here dimensionalized pressuring feeding styles (pressure to finish, pressure to soothe, and pressure to eat supplementary foods early in infancy). That only aspects of pressuring related to complementary food introduction were associated with breastfeeding duration suggests dimensionalizing pressuring feeding styles offers more insight to their connection with breastfeeding duration. While responsiveness to satiety and hunger cues has been consistently linked to reduced obesity risk $[20,40,41]$, there is less consistent evidence that early introduction of complementary foods increases obesity risk [42-46], particularly among breastfed infants $[47,48]$.

Few associations of breastfeeding duration with feeding styles were observed among mothers of toddlers. It is possible that greater length of recall by mothers of toddlers could have increased the greater chance of recall bias and misclassification relative to mothers of infants. However, maternal self-reports of breastfeeding are considered to be fairly reliable in the first three years of life [49]. It is also possible that the lack of association reflects a dynamic nature of feeding behaviors and interactions in toddlerhood. During toddlerhood, a number of intrinsic factors (within the developing child) are transacting with numerous extrinsic factors, including multiple caregivers responsible for feeding [50], modeling 
Table 7 ANCOVAt of Breastfeeding Duration as a Function of Maternal Feeding Styles among Toddlers

\begin{tabular}{|c|c|c|c|c|}
\hline IFSQ Subscale & $B F<3$ Mon $(n=21)$ & BF 3-6 Mon $(n=14)$ & BF $>6$ Mon $(n=41)$ & P-value \\
\hline \multicolumn{5}{|l|}{ Responsiveness Subscales } \\
\hline Satiety and Hunger Cues & $4.6(0.3)$ & $4.5(0.4)$ & $4.4(0.4)$ & 0.15 \\
\hline Attention \& Interactions & $3.8(0.7)$ & $3.7(0.7)$ & $3.7(0.7)$ & 0.84 \\
\hline \multicolumn{5}{|l|}{ Restriction Subscales } \\
\hline Amount of Food Consumed & $3.2(1.1)$ & $3.1(1.1)$ & $2.8(0.9)$ & 0.18 \\
\hline Diet Quality & $2.8(0.5)$ & $3.0(0.5)$ & $3.0(0.5)$ & 0.34 \\
\hline \multicolumn{5}{|l|}{ Pressuring to Eat Subscales } \\
\hline To Soothe & $2.3(0.8)$ & $2.1(0.6)$ & $2.3(0.8)$ & 0.72 \\
\hline Finishing Food & $2.6(0.9)$ & $2.5(0.8)$ & $2.3(0.7)$ & 0.56 \\
\hline Cereal* $^{*}$ & $2.6(1.2)$ & $2.4(0.8)$ & $1.4(0.5)$ & 0.00 \\
\hline \multicolumn{5}{|l|}{ Indulgent Subscales } \\
\hline Coaxing & $1.7(0.7)$ & $1.4(0.4)$ & $1.4(0.4)$ & 0.28 \\
\hline Pampering & $1.6(0.9)$ & $1.5(0.4)$ & $1.4(0.4)$ & 0.85 \\
\hline Permissive & $2.1(1.0)$ & $2.0(0.8)$ & $1.9(0.5)$ & 0.86 \\
\hline Soothing & $1.4(0.7)$ & $1.4(0.4)$ & $1.3(0.4)$ & 0.95 \\
\hline \multicolumn{5}{|l|}{ Laissez-faire Subscales } \\
\hline Attention & $2.1(0.7)$ & $2.1(0.7)$ & $1.8(0.6)$ & 0.20 \\
\hline Diet Quality & $2.1(0.8)$ & $2.3(0.6)$ & $2.4(0.9)$ & 0.57 \\
\hline \multicolumn{5}{|c|}{$\begin{array}{l}+ \text { Covariates included were maternal ethnicity marital status and maternal education level. } \\
\text { "p }<0.05 \text {. } \\
\text { ** } p<0.01 \text {. } \\
\text { Note: IFSQ Subscales were scored from 1-5, where behaviors are scored from " } 1 \text { "-never to " } 5 \text { "-always and beliefs are scored from " } 1 \text { "-disagree to " } 5 \text { "-agree. The } \\
\text { behavior portion of the Laissez-Faire Diet Quality Subscale was scored in descending order where "1"-always to " } 5 \text { "-never. IFSQ=Infant Feeding Styles } \\
\text { Questionnaire; BF }<3 \text { Mon=Breastfed less than } 3 \text { months group; BF3-6 Mon= Breastfed for 3-6 months group; BF }>6 \text { Mon= Breastfed for more than } 6 \\
\text { months group. }\end{array}$} \\
\hline
\end{tabular}

influences of siblings and peers [51], and the child's increasing involvement in family meals, which are often determined by the family's social clock rather than its individual members' hunger cues. Because the design of this study was not longitudinal, causal inferences are not appropriate; however the findings encourage longitudinal inquiry. Longitudinal research that spans late infancy into toddlerhood would offer more insights on whether breastfeeding duration in early infancy continue to influence maternal responsiveness during feeding, particularly considering the increasing intrinsic and extrinsic factors described here.

This study had a number of strengths and limitations. While ethnically diverse, this sample of mothers was generally college educated, of middle income, and married. Also, mothers in this sample had higher rates of overweight/obesity (72.6\%) than in the US adult population (64.1\%) [36]. However, weight was recorded in the postpartum period which likely inflated the rates for this sample. Results might be different in samples with more diversity in terms of these maternal characteristics, particularly for education level due to its positive association with breastfeeding duration [52]. This study was not able to ascertain the extent to which breastfeeding duration involved feeding at the breast, referred to as "direct breastfeeding", versus feeding human milk in a bottle. Direct breastfeeding has been linked to improved infant self-regulation of formula/human milk intake [49] and later satiety response [37], as well as reduced risk of accelerated weight gain [53]; thus future research in this area should differentiate between direct breastfeeding and feeding human milk in a bottle. Last, relative weight was included only as a potential covariate here. Future studies investigating breastfeeding behaviors and feeding styles would benefit from a longitudinal design which can assess relative weight at multiple time points into early childhood, particularly in larger samples which might identify even modest associations between breastfeeding behaviors, feeding styles, and child weight measures.

\section{Conclusions}

This research provides new evidence that longer breastfeeding duration may increase mothers' responsiveness to infant feeding cues after initiation of complementary feeding. It is clear that the first two years are highly important for obesity prevention [54] and that breastfeeding plays a role in prevention [55]. These findings suggest that breastfeeding might offer protection via responsive feeding during infancy, but that effects on maternal feeding beliefs and practices may not directly carry-over into toddlerhood. Further study is required to understand why breastfeeding might impact feeding styles and how that 
impact is related to obesity risk. If the behavioral factors of breastfeeding which lead mothers to engage in less obesogenic feeding behaviors during infancy are better understood, then promotion of healthier feeding behaviors could be extended to all caregivers during infancy, toddlerhood, and beyond, regardless of breastfeeding duration.

\section{Consent}

Written informed consent was obtained from the participant's parent/caregiver for the publication of this report.

\author{
Abbreviations \\ USDA: US Department of Agriculture; $\mathrm{BF}<3$ : Breastfeeding duration of 0-2.99 \\ months; BF3-6: Breastfeeding duration of 3-6 months; BF>6: Breastfeeding \\ duration of > 6 months; IFSQ: Infant feeding styles questionnaire; BMl: Body \\ mass index.
}

\section{Competing interests}

The authors declare that we have no competing interests.

\section{Authors' contribution}

Significant writer (KID, EAH), significant reviewer (EAH and JOF), manuscript concept/design (KID), data acquisition (JOF), and data analysis (KID). All authors have read and approved the final manuscript.

\section{Acknowledgements}

This work was supported by NIH K01 DK 61319-01 (Fisher), NIH DK 56350 (Hodges), RWJF 66523 (Hodges) and Nestle Infant Nutrition (Fisher).

\section{Author details}

'Department of Community \& Global Public Health, Arcadia University, College of Health Sciences, 450 S. Easton Road, 219 Brubaker Hall, Glenside, PA 19038-3295, USA. ${ }^{2}$ The University of North Carolina at Chapel Hill, School of Nursing, Chapel Hill, NC, USA. ${ }^{3}$ Department of Public Health, Temple University, College of Health Professions and Social Work, Philadelphia, PA, USA.

Received: 14 September 2012 Accepted: 10 April 2013 Published: 26 April 2013

\section{References}

1. Owen CG, Martin RM, Whincup PH, Davey-Smith G, Gillman MW, Cook DG: The effect of breastfeeding on mean body mass index throughout life: a quantitative review of published and unpublished observational evidence. Am J Clin Nutr 2005, 82(6):1298-1307.

2. Harder T, Bergmann R, Kallischnigg G, Plagemann A: Duration of breastfeeding and risk of overweight: a meta-analysis. Am J Epidemiol 2005, 162(5):397-403.

3. Arenz S, Ruckerl R, Koletzko B, von Kries R: Breast-feeding and childhood obesity-a systematic review. Int J Obes Relat Metab Disord 2004, 28:1247-1256.

4. Metzger MW, McDade TW: Breastfeeding as obesity prevention in the United States: a sibling difference model. Am J Hum Biol 2010, 22(3):291-296.

5. von Kries R, Koletzko B, Sauerwald T, von Mutius E: Does breast-feeding protect against childhood obesity? Adv Exp Med Biol 2000, 478:29-39.

6. Casazza K, Fontaine KR, Astrup A, Birch LL, Brown AW, Bohan Brown MM, Durant N, Dutton G, Foster EM, Heymsfield SB, et al: Myths, presumptions, and facts about obesity. N Engl J Med 2013, 368(5):446-454.

7. Gartner LM, Morton J, Lawrence RA, Naylor AJ, O'Hare D, Schanler RJ, Eidelman Al: Breastfeeding and the use of human milk. Pediatrics 2005, 115(2):496-506.

8. Bartok CJ, Ventura AK: Mechanisms underlying the association between breastfeeding and obesity. Int J Pediatr Obes 2009, 4(4):196-204.

9. Farrow CV, Blissett J: Controlling feeding practices: cause or consequence of early child weight? Pediatrics 2008, 121(1):e164-169.

10. Birch LL, Fisher JA: Appetite and eating behavior in children. Pediatr Clin North Am 1995, 42(4):931-953.
11. Costanzo P, Woody E: Domain-specific parenting styles and their impact on the child's development of particular deviance: The example of obesity proneness. J Soc Clin Psychol 1985, 3:425-445.

12. Birch LL, Fisher JO, Grimm-Thomas K, Markey CN, Sawyer R, Johnson SL: Confirmatory factor analysis of the Child Feeding Questionnaire: a measure of parental attitudes, beliefs and practices about child feeding and obesity proneness. Appetite 2001, 36(3):201-210.

13. Taveras EM, Scanlon KS, Birch L, Rifas-Shiman SL, Rich-Edwards JW, Gillman MW: Association of breastfeeding with maternal control of infant feeding at age 1 year. Pedatrics 2004, 114:e577-583.

14. Taveras EM, Rifas-Shiman SL, Scanlon KS, Grummer-Strawn LM, Sherry B, Gillman MW: To what extent is the protective effect of breastfeeding on future overweight explained by decreased maternal feeding restriction? Pediatrics 2006, 118(6):2341-2348.

15. Farrow C, Blissett J: Does maternal control during feeding moderate early infant weight gain? Pediatrics 2006, 118(2):e293-e298.

16. Fisher JO, Birch LL: Parents' restrictive feeding practices are associated with young girls' negative self-evaluation of eating. J Am Diet Assoc 2000, 100(11):1341-1346.

17. Birch LL, Fisher JO, Castro CN, Grimm-Thomas K, Sawyer R, Johnson SL: Confirmatory factor analysis of the Child Feeding Questionnaire: a measure of parental attitudes, beliefs and practices about child feeding and obesity proneness. Appetite 2001, 36(3):201-210.

18. Joyce JL, Zimmer-Gembeck MJ: Parent feeding restriction and child weight. The mediating role of child disinhibited eating and the moderating role of the parenting context. Appetite 2009, 52(3):726-734.

19. Hughes SO, Power TG, Orlet Fisher J, Mueller S, Nicklas TA: Revisiting a neglected construct: parenting styles in a child-feeding context. Appetite 2005, 44:83-92.

20. Thompson AL, Mendez MA, Borja JB, Adair LS, Zimmer CR, Bentley ME: Development and validation of the Infant Feeding Style Questionnaire. Appetite 2009, 53(2):210-221.

21. Fisher JO, Butte NF, Mendoza PM, Wilson TA, Hodges EA, Reidy KC, Deming $D$ : Overestimation of infant and toddler energy intake by $24-\mathrm{h}$ recall compared with weighed food records. Am J Clin Nutr 2008, 88(2):407-415.

22. Rhee KE, Lumeng JC, Appugliese DP, Kaciroti N, Bradley RH: Parenting styles and overweight status in first grade. Pediatrics 2006, 117(6):2047-2054.

23. Hughes SO, Shewchuk RM, Baskin ML, Nicklas TA, Qu H: Indulgent feeding style and children's weight status in preschool. J Dev Behav Pediatr 2008, 29(5):403-410.

24. Hoerr SL, Hughes SO, Fisher JO, Nicklas TA, Liu Y, Shewchuk RM: Associations among parental feeding styles and children's food intake in families with limited incomes. Int J Behav Nutr Phys Act 2009, 6:55.

25. Ogden CL, Carroll MD, Curtin LR, Lamb MM, Flegal KM: Prevalence of high body mass index in US children and adolescents, 2007-2008. JAMA 2010, 303(3):242-249.

26. Hughes SO, Anderson CB, Power TG, Micheli N, Jaramillo S, Nicklas TA: Measuring feeding in low-income African-American and Hispanic parents. Appetite 2006, 46(2):215-223.

27. Kumanyika SK: Environmental influences on childhood obesity: Ethnic and cultural influences in context. Physiol Behav 2008, 94(1):61-70.

28. Stettler N, lotova V: Early growth patterns and long-term obesity risk. Curr Opin Clin Nutr Metab Care 2010, 13(3):294-299.

29. Lohman TG, Roche AF, Martorell R: Anthropometric standardization reference manual. Champaign, IL: Human Kinetics Books; 1988.

30. Centers for Disease Control and Prevention: Breastfeeding trends and updated national health objectives for exclusive breastfeeding--United States, birth years 2000-2004. Morb Mortal Wkly Rep 2007, 56(30):760-763.

31. Costanzo PR, Woody EZ: Domain-specific parenting styles and their impact on the child's development of a particular deviance: the example of obesity proneness. J Soc Clin Psychol 1985, 4:425-445.

32. Kuczmarski RJ, Ogden CL, Grummer-Strawn LM, Flegal KM, Guo SS, Wei R, Mei Z, Curtin LR, Roche AF, Johnson CL: CDC growth charts: United States. Adv Data 2000, 314:1-27.

33. Li R, Jewell S, Grummer-Strawn L: Maternal obesity and breast-feeding practices. Am J Clin Nutr 2003, 77(4):931-936.

34. Street E, Lovelady CA, Ostbye T, Pendzich M, Fuemmeler BF: Breastfeeding as a predictor of body mass index in 2-year-old children at risk for overweight. J Fed Am Soc Exp Biol 2008, 22:1086.1086.

35. Faith MS, Berkowitz RI, Stallings VA, Kerns J, Storey M, Stunkard AJ: Parental feeding attitudes and styles and child body mass index: prospective 
analysis of a gene-environment interaction. Pediatrics 2004, 114(4):e429-436

36. Flegal KM, Carroll MD, Ogden CL, Curtin LR: Prevalence and trends in obesity among US adults, 1999-2008. JAMA 2010, 303(3):235-241.

37. Disantis Kl, Collins BN, Fisher JO, Davey A: Do infants fed directly from the breast have improved appetite regulation and slower growth during early childhood compared with infants fed from a bottle? Int J Behav Nutr Phys Act 2011, 8:89-100.

38. Brown A, Lee M: A descriptive study investigating the use and nature of baby-led weaning in a UK sample of mothers. Matern Child Nutr 2011 7(1):34-47.

39. Hsu HC, Fogel A: Stability and transitions in mother-infant face-to-face communication during the first 6 months: a microhistorical approach. Dev Psychol 2003, 39(6):1061-1082.

40. DiSantis Kl, Hodges EA, Johnson SL, Fisher JO: The role of responsive feeding in overweight during infancy and toddlerhood: a systematic review. Int J Obes (Lond) 2011, 35(4):480-492.

41. Hurley KM, Cross MB, Hughes SO: A systematic review of responsive feeding and child obesity in high-income countries. J Nutr 2011 141(3):495-501.

42. Reilly JJ, Armstrong J, Dorosty AR, Emmett PM, Ness A, Rogers I, Steer C, Sherriff A: Early life risk factors for obesity in childhood: cohort study. BMJ 2005, 330(7504):1357.

43. Schack-Nielsen L, Sorensen T, Mortensen EL, Michaelsen KF: Late introduction of complementary feeding, rather than duration of breastfeeding, may protect against adult overweight. Am J Clin Nutr 2010, 91(3):619-627.

44. Wilson AC, Forsyth JS, Greene SA, Irvine L, Hau C, Howie PW: Relation of infant diet to childhood health: seven year follow up of cohort of children in Dundee infant feeding study. BMJ 1998, 316(7124):21-25

45. Seach KA, Dharmage SC, Lowe AJ, Dixon JB: Delayed introduction of solid feeding reduces child overweight and obesity at 10 years. Int J Obes (Lond) 2010, 34(10):1475-1479.

46. Burdette HL, Whitaker RC, Hall WC, Daniels SR: Breastfeeding, introduction of complementary foods, and adiposity at $5 \mathrm{y}$ of age. Am J Clin Nutr 2006, 83(3):550-558.

47. Huh SY, Rifas-Shiman SL, Taveras EM, Oken E, Gillman MW: Timing of solid food introduction and risk of obesity in preschool-aged children. Pediatrics 2011, 127(3):e544-551.

48. Grote V, Schiess SA, Closa-Monasterolo R, Escribano J, Giovannini M, Scaglioni S, Stolarczyk A, Gruszfeld D, Hoyos J, Poncelet P, et al: The introduction of solid food and growth in the first $2 \mathrm{y}$ of life in formulafed children: analysis of data from a European cohort study. Am J Clin Nutr 2011, 94(6 Suppl):1785S-1793S.

49. Li RW, Fein SB, Grummer-Strawn LM: Do Infants Fed From Bottles Lack Self-regulation of Milk Intake Compared With Directly Breastfed Infants? Pediatrics 2010, 125(6):E1386-E1393.

50. United States Census Bureau, Laughlin L: Who's Minding the Kids? Child Care Arrangements: Spring 2005 and Summer 2006. In Edited by Bureau USC. Washington, DC; 2010; 2011:P70-121. Who's minding the kids? Child care arrangements: Spring 2010, detailed tables. Retrieved February 10, 2012, from http://www.census.gov/hhes/childcare/data/sipp/2010/tables. html.

51. Birch LL: Effects of Peer Models Food Choices and Eating Behaviors on Preschoolers Food Preferences. Child Dev 1980, 51(2):489-496.

52. Hendricks K, Briefel R, Novak T, Ziegler P: Maternal and child characteristics associated with infant and toddler feeding practices. J Am Diet Assoc 2006, 106(1):S135-S148.

53. Li R, Magadia J, Fein SB, Grummer-Strawn LM: Risk of bottle-feeding for rapid weight gain during the first year of life. Arch Pediatr Adolesc Med 2012, 166(5):431-436.

54. Harrington JW, Nguyen VQ, Paulson JF, Garland R, Pasquinelli L, Lewis D: Identifying the "Tipping Point" Age for Overweight Pediatric Patients. Clin Pediatr (Phila) 2010, 49(7):638-643.
55. Services USDoHaH: The Surgeon General's Call to Action to Support Breastfeeding. In Edited by U.S. Department of Health and Human Services Oot, General S. Washington, DC; 2011. U.S. Department of Health and Human Services. he Surgeon General's Call to Action to Support Breastfeeding. Washington, DC: U.S. Department of Health and Human Services, Office of the Surgeon General; 2011.

doi:10.1186/1479-5868-10-53

Cite this article as: DiSantis et al:: The association of breastfeeding duration with later maternal feeding styles in infancy and toddlerhood: a cross-sectional analysis. International Journal of Behavioral Nutrition and Physical Activity 2013 10:53.

\section{Submit your next manuscript to BioMed Central and take full advantage of:}

- Convenient online submission

- Thorough peer review

- No space constraints or color figure charges

- Immediate publication on acceptance

- Inclusion in PubMed, CAS, Scopus and Google Scholar

- Research which is freely available for redistribution

Submit your manuscript at www.biomedcentral.com/submit
C) BioMed Central 